\title{
¿LA PARTICIPACIÓN CIUDADANA SE HA INTEGRADO AL PROCESO DE PLANIFICACIÓN TURÍSTICA EN CANCÚN, MEXICO?
}

\author{
Guadalupe ALDAPE PÉREZ
}

Este artículo presentará el marco conceptual de la planificación turística en México que encuentra su origen en los preceptos de la disciplina de la planificación urbana y regional británica y la planificación turística de la OMT -Organización Mundial del Turismo-. En un lapso de cuarenta años, el proceso ha pasado de ser controlado por las organizaciones gubernamentales a permitir la participación ciudadana. Este estudio se enfocará en el plan parcial de Punta Cancún, que es el nodo comercial más importante de la zona turística de Cancún.

A lo largo de este escrito se resaltarán temas y cuestiones relacionadas con la metodología original y las posibles contradicciones entre rigidez y rigor dentro del ejercicio de planificación urbana de la zona comercial más importante en el primer centro turístico planificado en México. Actualmente la metodología ha permitido la flexibilidad en el sistema mediante la introducción de distintos actores a la escena de la planificación urbana. No obstante, surgen dudas del punto hasta el cual se ejerce control y cuál es la mejor forma de permitir la participación ciudadana e introducir flexibilidad en el proceso de planificación urbana y turística sin poner en riesgo el interés público.

Planificación urbana, ordenación territorial, participación ciudadana, interés público, flexibilidad

\section{HAS PUBLIC PARTICIPATION BEEN INTEGRATED TO THE TOURISM PLANNING PROCESS IN CANCUN, MEXICO?}

This article will present the conceptual framework of tourism planning on the Mexican coastline that has been based on the principles of the city and regional planning system in the UK. In a forty-year lifespan, this process has evolved from being controlled by Central Government to allowing public participation. This study will focus on the Punta Cancun Plan, which is the main commercial node in the touristic zone of Cancun.

This article will highlight issues related to the original methodology and possible contradictions between rigidity and rigour in the urban planning method for the most important commercial zone in Cancun. Nowadays the methodology has allowed the introduction of diverse actors to the city planning scene. Though questions have been raised about the extent to which public participation could be introduced and controlled in the planning process and what it is the best practice to introduce flexibility without risking the public interest in urban and tourist planning.

City planning, territorial ordinance, public participation, public interest, flexibility 


\section{INTRODUCCIÓN}

"If planning were judged by results, that is, by whether life followed the dictates of the plan, then planning has failed everywhere it has been tried. No one, it turns out, has the knowledge to predict sequences of actions and reactions across the realm of public policy, and on one has the power to compel obedience."

Wildavsky, 1987

La planificación turística en el litoral mexicano tiene escasamente cuatro décadas de existencia dentro de este lapso sobresale el caso de Cancún como ejemplo pionero en el desarrollo turístico planificado ex nibilo. El tema es de gran interés para los estudiosos del urbanismo y la ordenación territorial por sus grandes lecciones en cuanto a metodología y políticas encaminadas al desarrollo social y económico de regiones en alto grado de marginación.

Este artículo presentará el marco conceptual de la planificación turística en México que encuentra su origen en los preceptos de la disciplina de la planificación urbana y regional británica y la planificación turística de la OMT -Organización Mundial del Turismo-. El proceso ha pasado de ser controlado por las organizaciones del gobierno Federal, Estatal y Municipal a permitir la participación de grupos privados. Este caso se enfocará en uno de los planes parciales de Punta Cancún.

\subsection{El sistema de planificación turística de sol y playa}

El sistema de planificación turística del litoral mexicano se puede comparar en gran medida con los preceptos conceptuales y las buenas prácticas de la planificación turística de la OMT, que a su vez derivan de la metodología y los principios de la disciplina de la planificación urbana británica. La disciplina de la planificación urbana moderna tiene su origen en Gran Bretańa, como respuesta a la industrialización, la rápida urbanización y los temas asociados a estos movimientos dentro de los cuales podemos referir como uno de sus resultados más recientes al turismo masivo de sol y playa en países en vías de desarrollo.

El marco conceptual de la planificación urbana y regional en Reino Unido se centra en el proceso de determinación de usos de suelo, la elaboración de 
la legislación y la observancia de la ley para ordenar el proceso de desarrollo. El objetivo principal del sistema de planificación británico es regular el desarrollo y el uso de suelo con respecto al "interés público" (Cullingworth et Nadin, 1964: 2). Debido a la dificultad de definir el interés público en cada disputa en el proceso de desarrollo de un sitio y la imposibilidad de equiparar la distribución de los costos y beneficios en dicho proceso, las políticas de planificación urbana y regional se encuentran en una continua revisión y dependiendo de la temática, se permite la flexibilidad por medio de la participación ciudadana o la discreción de las autoridades para compensar a los afectados.

En el ejercicio de planificación del turismo de sol y playa por el "interés público" en regiones con alto grado de marginación, Inskeep (1991:26) recomienda que éste sea llevado a cabo por los gobiernos centrales. En este orden de ideas, ha sido ampliamente reconocido por varios estudiosos del fenómeno turístico masivo de sol y playa, el papel de los gobiernos centrales, fundamental en el éxito de la planificación turística.

En regiones con incipiente número de población, como fue el caso de Cancún en los ańos 70, el gobierno Federal tuvo como responsabilidad el velar por "el interés público" o específicamente los intereses de la región que incursiona en el proceso de desarrollo de un destino turístico.

El gobierno Central es la entidad facultada para redactar las leyes, disponer y administrar los recursos presupuestales nacionales, y proteger los recursos naturales de la nación. Pearce (1989:42) señala que, sobre todo, los gobiernos centrales son las únicas entidades capaces de solicitar o garantizar un préstamo de envergadura tal que pueda soportar la inversión en infraestructuras y políticas encaminadas al desarrollo del turismo.

La OMT (2001:10) refiere que "para que el turismo se desarrolle de una forma sostenible, se requiere un marco físico, normativo, fiscal y social apropiado, algo que, por supuesto, solo los gobiernos o las autoridades" deben proporcionar. "A menudo ofrecen asimismo la infraestructura básica necesaria para el turismo, como carreteras, aeropuertos y comunicaciones, y crean el marco jurídico en el que opera la industria”.

Gunn (1994) explica que en muchos países los gobiernos pueden ser propietarios de una serie de bienes patrimoniales que, además de ser atracciones turísticas, pueden ser áreas de conservación de recursos naturales. Asimismo, algunos sectores gubernamentales son propietarios y administradores de las infraestructuras que abastecen al turismo, por ejemplo el agua potable, el drenaje, la luz eléctrica y el alumbrado público y las comunicaciones. Además, en algunos países, la promoción y publicidad turística ha estado a cargo de ciertas instancias gubernamentales. 
Pearce (1989:42-43) explica que el Gobierno Central tiene el poder de regular numerosas áreas que influyen en la demanda y el desarrollo turístico. Sin embargo, existen además otras organizaciones que colaboran y tienen un papel destacado y quizás de mayor impacto inmediato en el desarrollo turístico. De tal suerte, afirma que la más directa y explícita manifestación de la participación del Gobierno Central en el desarrollo turístico se da a través de la Administración Turística Nacional (National Tourism Administration ATN).

Las AATTNN han sido definidas por la OMT (WTO, 1979:11) como las autoridades de la administración estatal central, u otra organización oficial a cargo del desarrollo turístico a nivel nacional. También se han encontrado referidas como ONT Organización Nacional de Turismo (en inglés NTO-National Tourism Organization) u OGT Oficina Gubernamental de Turismo (GTO-Government Tourism Offices).

Dependiendo de la organización gubernamental de cada nación, estas instituciones pueden llegar a ser ministerios, pueden constituirse como una parte de un departamento gubernamental, o pueden ser organizaciones con su propia personalidad jurídica, como por ejemplo organizaciones o corporaciones gubernamentales bajo la supervisión de la administración central.

La OMT explica que, en sus inicios, las AATTNN, OONNTT u OOGGTT "no solo construyeron los cimientos del turismo de sus países, sino que se hicieron responsables también de su gestión. Se convirtieron en hoteleros, agencias de viajes, tour operadores y transportistas. Además, las competencias depositadas por los gobiernos en sus AATTNN en aquellos primeros días eras muy amplias y abarcaban todas las áreas de las actividades turísticas, incluido el desarrollo de la hostelería y la financiación” (OMT, 2001:11).

Por su parte, Lawson (1995:132) afirma que en el desarrollo de centros turísticos integrales se encuentran las agencias gubernamentales como instancias promotoras y coordinadoras para atraer la inversión extranjera, servir como un modelo para futuro desarrollo, incentivar la economía local y regional, y proveer alojamiento económicamente accesible al turismo doméstico.

\subsection{La planificación turística en el litoral mexicano}

Dentro del marco conceptual anteriormente enunciado, encontramos el caso mexicano caracterizado por dos autoridades gubernamentales en materia de turismo. Por la parte ejecutiva, se encuentra la agencia planificadora FONATUR -Fondo Nacional de Fomento al Turismo- en la condición de una organización turística nacional (OTN) con recursos propios, reserva territorial y libertad de decisión bajo el común acuerdo de un Comité Técnico. Por la parte legislativa se encuentra una Secretaría de Estado, la Secretaría de Turismo en el papel de la ATN - Administración Turística Nacional-, la cual 
toma a su cargo la legislación del turismo y su correspondencia con los planes y las autoridades de la administración central.

A principios de los 70, el Gobierno mexicano, mediante la gestión de créditos de la banca de desarrollo internacional enfocados a centros turísticos de sol y playa, desarrolló Cancún, en el extremo nororiental de la Península de Yucatán. Este sitio se encontraba con grandes carencias de actividades económicas robustas, y rezagado del desarrollo social del centro y norte del país. De tal suerte, aquella región de Yucatán ha resurgido a la actividad económica mediante el desarrollo del primer centro turístico planificado exnovo bajo esta modalidad, conocido como Centro Integralmente Planeado -CIP-.

Cancún, además de ser el primer CIP ha sido el más exitoso en términos económicos. Por lo anterior, ha sido ejemplo para los subsecuentes centros turísticos desarrollados por FONATUR. La metodología aplicada en Cancún ha sentado precedente en el desarrollo de cuatro CCIIPP en el litoral mexicano: Los Cabos, Ixtapa, Loreto y Huatulco.

La actividad de planificación urbana en los inicios de Cancún se ha caracterizado por el papel de FONATUR, originalmente INFRATUR, como agencia de gestión, administración y ejecución de acciones de fomento al turismo al mismo tiempo. Al inicio de su actuación, esta organización ha tenido que trabajar no nada más como un catalizador del desarrollo. A principios de los 1970, aquella agencia cuya misión fue poner en marcha a Cancún en la condición de centro turístico integral de primer orden, incursiona en el terreno de la construcción, el desarrollo y la promoción del sitio. La experiencia de planificación turística de FONATUR en sus momentos iniciales, específicamente en el caso de Cancún se pretendía sirviera de ejemplo e incentivo al desarrollo turístico en el sitio.

FONATUR fue constituido como fideicomiso ${ }^{1}$ de crédito de acuerdo con la Ley de Fomento al Turismo el 28 de enero de 1974 (FONATUR, 1982) el cual colabora con los objetivos de NAFIN -Banca Nacional Financieradesarrollando, planificando y financiando la actividad turística nacional.

\footnotetext{
1 El fideicomiso es un acto jurídico que se hace constar en un contrato, en cuya formación intervienen las siguientes tres personas jurídicas, los bienes o derechos y el fin lícito y determinado:

- El fideicomitente es la persona que expresa voluntad de establecer el fideicomiso y quien separa de su patrimonio los bienes o derechos para cederlos al fiduciario.

- El fiduciario es la persona o institución de crédito autorizada por el Estado, constituida en sociedad y a la que temporalmente se le trasmite la propiedad de los bienes o la titularidad de los derechos del fideicomitente. El fiduciario recibe como fin lícito y determinado la exclusiva realización y cumplimiento de la voluntad del fideicomitente y los bienes y derechos del mismo, quedando, temporalmente, como propietario y titular. Los bienes, derechos y las ganancias obtenidas de este negocio jurídico serán entregados al fideicomisario, quien será el beneficiario del fideicomiso.

- El fideicomisario, es el beneficiario del provecho que el fideicomiso implica.

El fideicomiso no otorga derechos reales al fideicomisario. Solo le concede derechos personales para exigir al fiduciario el cumplimiento de los fines del fideicomiso y reclamar daños y perjuicios que la actuación del fiduciario le hayan causado.

Entre los antecedentes del fideicomiso encontramos en Ramírez (1981) que el Poder Legislativo hace un traslado de los principios del fideicomiso inter vivos y el Use del Reino Unido, a la legislación mexicana. El fideicomiso tiene como antecedente inmediato el fideicomiso inter vivos. El desarrollo del Use, cuyo empleo se remonta al siglo XII, derivó en la integración del instrumento llamado Trust.
} 
FONATUR tiene como antecedente dos organizaciones públicas que habían trabajado previamente a favor del turismo: FOGATUR e INFRATUR. El Fondo de Garantía y Fomento de Turismo (FOGATUR) fue creado el 14 de noviembre de 1956 con el objeto de otorgar créditos para estimular la inversión turística nacional bajo la dirección de Nacional Financiera.

Por su parte, bajo la figura de fideicomiso, con fecha de 22 de mayo de 1969 se firmó un contrato entre la Secretaría de Hacienda y Crédito Público y el Banco de México, para constituir el Fondo de Promoción e Infraestructura Turística (INFRATUR), cuyos objetivos eran los de promoción y realización de obras de infraestructura relacionadas con el programa del Gobierno Federal para el desarrollo de nuevos centros turísticos de importancia y la mejora sustancial de otros que habían mostrado su potencialidad como centros de atracción turística.

De tal suerte el día 29 de marzo de 1974 fue creado el Fondo Nacional de Fomento al Turismo (FONATUR), por contrato celebrado entre la Secretaría de Hacienda y Crédito Público en su carácter de Fideicomitente único del Gobierno Federal y Nacional Financiera, como fiduciaria. De esta manera, FONATUR forma parte del sector público paraestatal, se encuentra bajo la coordinación sectorial de la Secretaría de Turismo y ajusta sus acciones al Plan Nacional de Desarrollo y al Programa Nacional de Turismo (FONATUR, 2010).

La primera etapa de actuación de FONATUR coincide con el relato de la OMT (2001:10-11) en el que menciona que "En el primer periodo del desarrollo turístico..., los gobiernos desempeñaron un papel pionero. Su función se consideraba esencial...para construir las infraestructuras e instalaciones básicas necesarias para abrir al turismo determinadas zonas de un país y fomentar su crecimiento. En aquel momento no cabía espera que el sector privado acudiera a ofrecer financiación hasta que se hubiese creado un clima de confianza”. La figura 1 muestra una tabla con la inversión inicial de la fundación de Cancún. Se puede apreciar que el $22.05 \%$ de la inversión la llevaron a cabo distintas Secretarías de Estado con el objetivo de proveer al sitio de las infraestructuras básicas como son obras públicas, comunicaciones y transportes, aeropuertos y servicios auxiliares, recursos hidráulicos y luz eléctrica.

Fig.1: Inversión inicial para el lanzamiento del proyecto de Cancún. Fuente: BID, 1971:19; FONATUR, 1982:19. Elaboración propia.

\begin{tabular}{|l|c|c|}
\hline \multicolumn{1}{|c|}{ Entidad inversora } & Participación & Inversión (Dólares) \\
\hline $\begin{array}{l}\text { Obras Públicas (SOP); Recursos } \\
\text { Hidráulicos (SRH); Comunicaciones y }\end{array}$ & $22.05 \%$ & $10,384,995$ \\
$\begin{array}{l}\text { Transportes (SCT); Aeropuertos y } \\
\text { Servicios Auxiliares y Comisión Federal } \\
\text { de Electricidad (CFE) }\end{array}$ & $32.30 \%$ & $\mathbf{1 5 , 2 1 2 , 4 8 6}$ \\
\hline INFRATUR & $45.65 \%$ & $\mathbf{2 1 , 5 0 0 , 0 0 0}$ \\
\hline Banco Interamericano de Desarrollo & $\mathbf{1 0 0 . 0 0 \%}$ & $\mathbf{4 7 , 0 9 7 , 4 8 1}$ \\
\hline
\end{tabular}


Como organización de reciente creación, INFRATUR no contaba con reputación o resultados palpables acerca de sus objetivos. El sector privado local no tenía fuerza suficiente para participar activamente en el proceso de desarrollo turístico. El sector privado internacional se mostraba escéptico al considerar riesgoso invertir en una playa desierta sin infraestructura para que se volviera un negocio rentable (FONATUR, 2006:12). La incertidumbre del sector privado en la fase inicial de desarrollo llevó a la agencia a tomar acción en negocios turísticos con el apoyo económico de las organizaciones internacionales de desarrollo.

En sus orígenes, FONATUR no solamente ha tenido que urbanizar, diseñar y construir las instalaciones turísticas, sino que también ha tenido que crear la sinergia para mantener y hacer crecer estos negocios. FONATUR ha participado en el proceso de creación e innovación y además ha colaborado en la implementación, la administración y el fortalecimiento de varios asuntos turísticos. Por ejemplo, en el caso del aeropuerto de la ciudad de Cancún, la actividad de planificación ha comprendido la solicitud de fondos, el diseño urbano, el diseño arquitectónico, la construcción y la implementación de un esquema de manejo de flujos de las aerolíneas (BID, 1971:8).

En Cancún, la participación de INFRATUR tomó el papel de socio hotelero y promotor con un esquema de proyecto, parcela y crédito para incentivar la inversión hotelera. Por ejemplo, en el hotel Cancún Caribe, uno de los primeros hoteles en Cancún, surgió de una inversión inicial de varios bancos privados del Distrito Federal, Monterrey y Mérida para construir 208 cuartos y 23 villas, INFRATUR aportó al negocio la parcela, recuperando 19\% de las acciones. Poco después, en el Playa Blanca, INFRATUR preparó un paquete de proyecto, terreno y crédito para construir un hotel de 72 cuartos. (Martí, 1985: 48-49).

Con el fin de animar a los inversores, después del hotel Playa Blanca INFRATUR adoptó aquel esquema localizando las parcelas urbanizables, elaborando el proyecto de los hoteles e incluso iniciando la construcción de los mismos. Esta estrategia sirvió para convencer a los nuevos inversores. El tercer hotel fue erigido fue el hotel Bojórquez que inició con un hotel de veinticinco cuartos junto al Playa Blanca.

Así fue como varias sociedades de crédito e inversión se interesaron en la hotelería en Cancún. Por ejemplo BANAMEX (Banco Nacional de México) compró terrenos en la Punta Cancún donde decidió construir una sucursal del hotel Camino Real. Al mismo tiempo, la empresa paraestatal Nacional Hotelera inició la edificación del hotel Presidente. Y en la Punta Nizuc, INFRATUR edificó un hotel de 300 cuartos que operaría posteriormente el Club Mediterranée (Idem: 49-50). 
En el caso de Cancún podemos afirmar que el ejercicio de planificación urbana y turística estuvo mayormente controlado por las instituciones paraestatales lo que trajo como consecuencia alto grado de rigidez en todo el proceso. En sus inicios, la agencia FONATUR se encargó de desarrollar el sitio de acuerdo a los planes y presupuestos autorizados, sin tener que tomar en cuenta opiniones de la población local que hasta esos momentos era inexistente. Sin embargo, conforme la ciudad crece y se vuelve más compleja en sus procesos socio-económicos, y las autoridades municipales empiezan a tomar las riendas del desarrollo urbano, la figura de FONATUR hasta cierto punto empieza a sobrar en la planificación turística del sitio. Es importante recalcar que el movimiento de devolución de poder a las autoridades municipales por parte de FONATUR ha evitado la duplicación de roles permitiendo el fortalecimiento del poder municipal.

\subsection{La metodología de la planificación turística}

En los inicios de la planificación urbana como disciplina, hubo un gran énfasis en la preparación de un plan director que resumía gráficamente la ordenación territorial y el control de los patrones de desarrollo a través de la designación de usos de suelo. Sin embargo, este tipo de planes supone un sistema rígido que cuenta con poca flexibilidad para asimilar los cambios sociales, tecnológicos, medioambientales y cualquier otro, a largo plazo. En los orígenes, Cancún no es la excepción a esta regla, el Plan de 1982 imprime el esquema de ordenación territorial con la zonificación de la ciudad y el desarrollo de proyectos ejecutivos para las tres distintas etapas de desarrollo del sitio.

Sin embargo la disciplina de la planificación urbana ha evolucionado buscando la introducción de la flexibilidad en esquemas de desarrollo que no sean un documento rígido y riguroso. Cullingworth et Nadin (2002: 2) afirman que la planificación urbana en Reino Unido contaba con el modelo de "zoning" o zonificación de usos de suelo y densidades constructivas y habitables por colores, pero recientemente ha tomado una posición más flexible.

Las nuevas tendencias en la planificación apuntan a un proceso continuo que mantenga claros objetivos de desarrollo y al mismo tiempo sea flexible a ciertas circunstancias cambiantes. La flexibilidad en el proceso de planificación depende del continuo rastreo y estadística del proceso de desarrollo, así como de la evaluación de nuevas tendencias. Además la planificación tiende a un espectro inclusivo cada vez más amplio en el cual están comprendidos todos los aspectos del sitio, del medio ambiente, todos los actores sociales y las implicaciones en los tres niveles de gestión gubernamental. 
En este orden de ideas, Inskeep (1991:26) afirma que con el fin de obtener patrones de desarrollo efectivos y generar los menores daños en el medio ambiente y la sociedad, todos los aspectos del desarrollo tienen que ser tomados en cuenta, integrados y planificados. Actualmente la planificación urbana aplica un enfoque en el que reconoce a distintos sectores involucrados en el desarrollo, como son los políticos a distintos niveles de gobierno, la industria de desarrollo, los propietarios privados y el público en general.

Un aspecto importante en la planificación urbana, que ha sido integrado últimamente, es la participación pública en el proceso de toma de decisiones. Esto se basa en el hecho de que los primeros beneficiarios o perjudicados por las acciones de la planificación urbana, son los propietarios y residentes de un área. En consecuencia, es a ellos a quien se debe dar oportunidad de participar en la planificación del desarrollo futuro y expresar sus puntos de vista, su deseo o rechazo en operaciones para su comunidad. En este sentido, el punto de vista de la población local se ha vuelto tan importante que para las autoridades turísticas Barba et Pié (1996: 66) afirman que, hoy en día, en orden de conseguir la continuidad de operaciones, las AATTNN buscan lograr la aprobación de los ciudadanos y toman en cuenta su opinión en los procesos de desarrollo urbano y regional.

Otro tema que ha sido integrado recientemente a la planificación urbana es la preocupación por la degradación del medio ambiente y del acervo cultural, que resulta de diversas prácticas de desarrollo. El debate a finales de los ańos 80 ha llevado a acuñar el término desarrollo sostenible (United Nations, 1987; Inskeep, 1991:26-28) que engloba no solamente las consideraciones de impacto medioambiental sino las del impacto social.

En síntesis, el papel de la planificación turística actual es aquel que va encaminado a la identificación, diseño, desarrollo y administración de áreas turísticas donde la concertación y colaboración entre partes involucradas, la comunidad y el medio, debe ir por encima de los intereses individuales. Para este fin, la autoridad planificadora debe ser un coordinador y un catalizador de acciones de los distintos actores.

\section{EL DESARROLLO TURÍSTICO EN PUNTA CANCÚN}

Originalmente la ordenación del territorio del noroeste de la Península de Yucatán podría afirmarse que se debe en gran medida al Plan Director de Cancún de 1982 elaborado por FONATUR. A pesar de que el desarrollo en el sitio de Cancún inició en 1970, el documento de 1982 es el primer proyecto urbanístico de Cancún que se ha encontrado. Aquel documento no tiene el formato característico de un plan director ni tampoco fue publicado en el diario oficial, sin embargo explica los antecedentes del turismo planificado 
en México, las políticas nacionales y la intención del Gobierno Federal en los desarrollos de centros turísticos integrales a lo largo del litoral mexicano y como punto de partida desarrolla el proyecto de Cancún.

El plan ordena la ciudad de Cancún en tres zonas diferenciadas: una turística, sobre la barrera postarrecifal que se conoce como Isla Cancún; la zona residencial y de servicios sobre el extremo norte del polígono en la placa continental y el aeropuerto, al sur de la zona habitacional, fuera del polígono de FONATUR.

El Plan 1982 es un documento que sigue las buenas prácticas de la elaboración de un "plan maestro" o "master plan" en la tradición británica del "zoning". Desarrolla el sitio a partir de una serie de estudios sociales, económicos, culturales y medioambientales, que fueron vanguardistas en la elaboración de planes de desarrollo urbano en el contexto mexicano a principios de los 70 . El esquema conceptual se puede apreciar en la figura 1 y la carta urbana de usos de suelo de 1982 estipulando densidades constructivas y de ocupación en la figura 2 .

Fig.2: Criterio conceptual del planeamiento de la ciudad de Cancún. Fuente: FONATUR, 1982, p. 66.

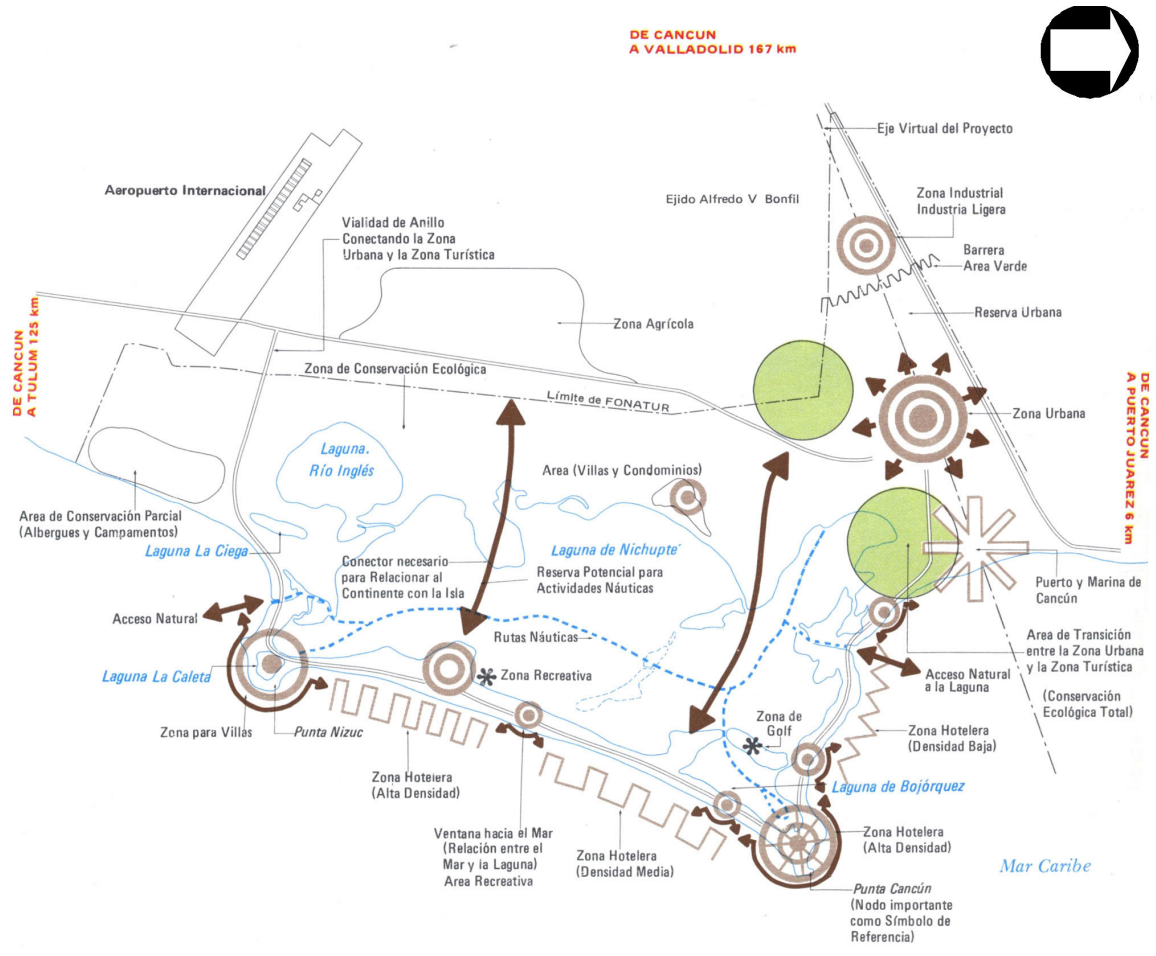




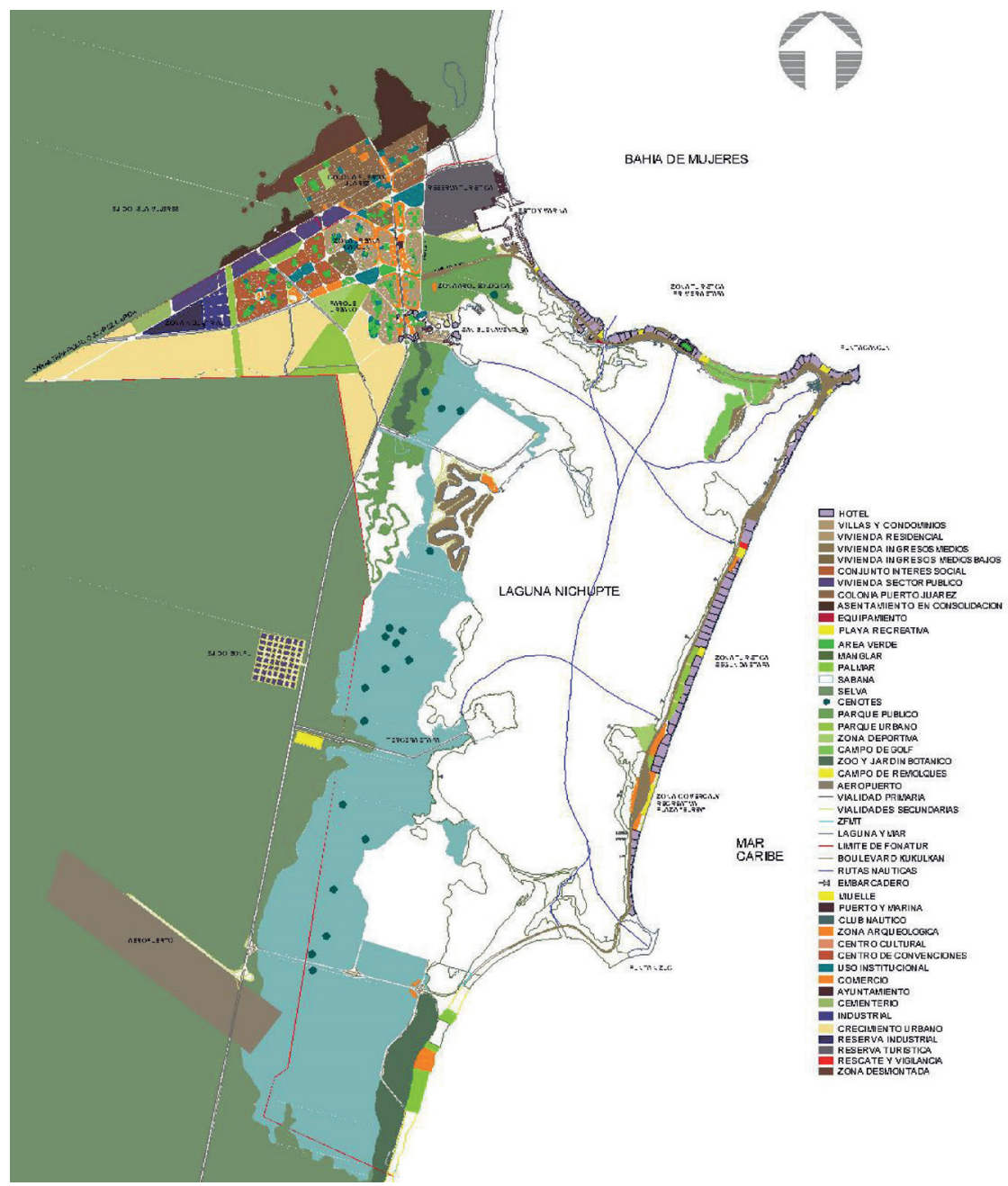

Fig.3: Plano de zonificación. Plan Director de Cancún 1982. Fuente: FONATUR. Elaboración propia.

Recientemente se ha encontrado que en los inicios de la planificación turística de Cancún no se tomaron en cuenta temas relacionados con el desarrollo sostenible como son la participación ciudadana o el impacto al medio ambiente al grado que se considera actualmente. El escenario del que partió el desarrollo en Cancún con el Plan de 1982 (FONATUR, 1982) no contaba con población local por lo tanto era difícil conocer el perfil de la población que viviría en el sitio y prever la opinión o las necesidades de tal grupo. 
Asimismo desde el punto de vista medioambiental, es posible que la riqueza natural fuera tan vasta que pareciera inacabable y carente de cuidados para su preservación. Sin embargo hoy es indispensable tomar en cuenta todos estos temas y otros no previstos todavía, pues pueden ser determinantes en la planificación turística y urbana y el desarrollo de ciudades y regiones a corto, mediano y largo plazo.

Actualmente muchas de las características socio-económicas y políticas han cambiado en Cancún. Esto ha resultado en el interés en la participación de grupos de actores locales en el desarrollo del sitio. Al mismo tiempo, se ha presentado la devolución del poder de FONATUR a las autoridades municipales. Lo anterior es evidente en el análisis de los tres planes de desarrollo urbano que ha tenido Cancún: el Plan Director de Cancún de 1982, elaborado por FONATUR; el Plan Director de Desarrollo Urbano de la ciudad de Cancún en 1993 publicado por el Gobierno del Estado de Quintana Roo y en 2005 el Programa de Desarrollo Urbano del Centro de Población de la Ciudad de Cancún elaborado por el Municipio de Benito Juárez.

Otro aspecto a destacar, es que el más reciente documento se ha encargado de propiciar la participación ciudadana permitiendo la elaboración de once planes y programas parciales de desarrollo elaborados directamente por los grupos interesados en cada zona de la ciudad. Nos enfocaremos al análisis de uno de estos documentos para resaltar temas de interés en el proceso de planificación: el Programa Parcial de Reordenamiento Urbano Turístico de Punta Cancún 2001. Aquel documento surge del interés de los hoteleros y comerciantes de esta zona por proponer mejoras para acrecentar la actividad económica de la Punta Cancún.

Dicho programa describe la problemática existente antes de la elaboración del documento y a la Punta Cancún como una zona con "diversidad de estilos arquitectónicos, que si bien en su individualidad tiene valor, en el conjunto pierden armonía, desintegrando y fraccionando la imagen urbana" (Gobierno del Estado de Quintana Roo, 2001:5).

Además el documento menciona los siguientes problemas detectados: presencia de parcelas baldías; construcciones inconclusas; deterioro de edificios comerciales; insuficiencia de espacios públicos; subutilización y deterioro del área del centro de convenciones; sobrecarga de servicios públicos; rezago en el suministro de agua potable; carencia de un paseo peatonal; falta de una imagen integral; problemas de vialidad e insuficiencia de lugares de estacionamiento (Ídem:5-6). 
Las propuestas del Programa de Punta Cancún se dividen en los siguientes proyectos:

- Remodelación del Boulevard Kukulkán a través de la creación de dos carriles de circulación adicionales a los existentes, en el tramo entre las parcelas 1 (Hotel Presidente) y 5-B (Playa Caracol).

- Construcción de malecón (paseo peatonal) y edificios de estacionamiento. El malecón sustituye a la vialidad existente en el tramo comprendido entre las parcelas 1 y 6 -A, frente a la laguna Bojórquez. El estacionamiento tendrá capacidad de alrededor de 355 lugares.

- Remodelación de las plazas comerciales Mayfair; Lagunas; Costa Blanca; Terramar; Caracol I y II; y las parcelas baldías 1, 2, 3, 4, 5, 6A y la zona comercial 2. Estas áreas comerciales se integraran con el proyecto del malecón público hacia la laguna.

- Remodelación del centro de convenciones; plaza El Parián; museo del Instituto Nacional de Antropología e Historia (INAH); construcción de torre panorámica y estacionamiento sobre las parcelas 1, 1A, 2, la zona comercial 1 y el centro de convenciones.

- Remodelación de centros nocturnos de las parcelas 3 - 7 y la zona comercial 2.

- Remodelación de la plaza comercial La Fiesta, El Zócalo en las parcelas 1, 2,3 y la zona comercial 3 .

- Remodelación de la Playa Caracol, muelle de aliscafo, subestación eléctrica y cárcamo de bombeo en las parcelas 5-B, 5-B1, 5-B2, 5-B3, 5-B4, y 5-B5.

- Construcción de un hotel en las parcelas 9-B1 y 9-B2 de un número máximo de cuartos de 265; COS de 60\% y CUS de 3.30. Altura máxima de 15 niveles o $60 \mathrm{mts}$.

A cambio de la construcción del hotel en las parcelas 9-B1 y 9-B2 (proyecto 8), el grupo inversor se compromete a la ampliación de un acceso peatonal de $24 \mathrm{mts}$ en la parcela 9-B1, que sumados a los $6 \mathrm{mts}$. del actual acceso peatonal de la playa Gaviota Azul (parcela 9-B2), dará un ancho total de $30 \mathrm{~m}$.

El grupo inversor también aportará una cantidad en efectivo; la mitad de esta aportación se destinará al pago de derechos de conexión y mejoramiento de servicios públicos. La mitad restante serán aportados para la ejecución de obra pública en beneficio de la comunidad previa aprobación del Cabildo (Idem:95-102). 

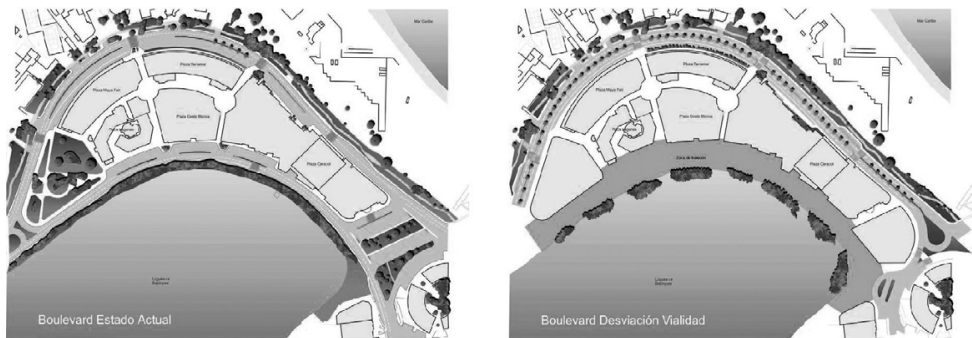

Fig.4: Estado actual del Boulevard Kukulkán y propuesta del Malecón hacia la Laguna Bojórquez. Fuente: Ayuntamiento Benito Juárez, 2001.
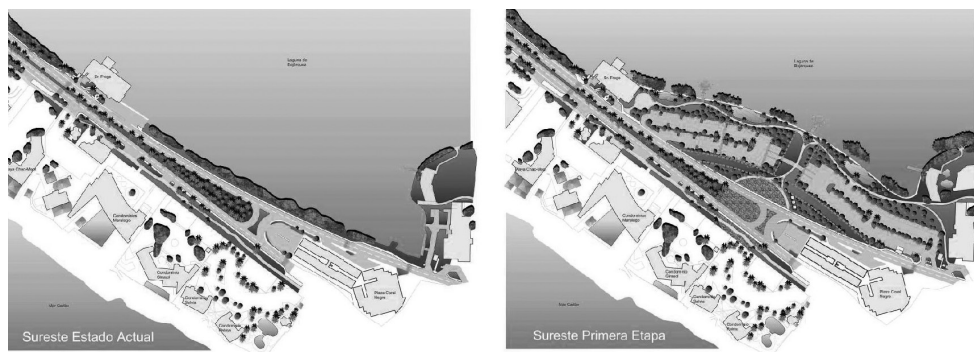

Fig.5: Proyecto de ampliación de zonas de estacionamiento sobre el Sistema Lagunar Nichupté. Fuente: Ayuntamiento Benito Juárez, 2001.
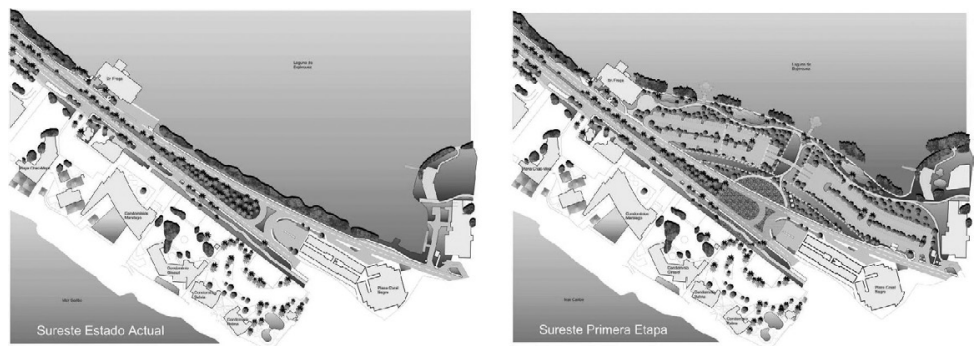

Fig.6: Proyecto de ampliación de zonas de estacionamiento sobre el Sistema Laguna Nichupté. Fuente: Ayuntamiento Benito Juárez, 2001.
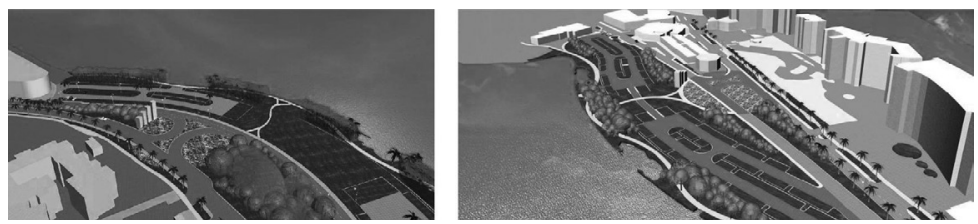

Fig.7: Proyecto de paseo comercial peatonal y pasos hacia el frente de playa. Fuente: Ayuntamiento Benito Juárez, 2001. 


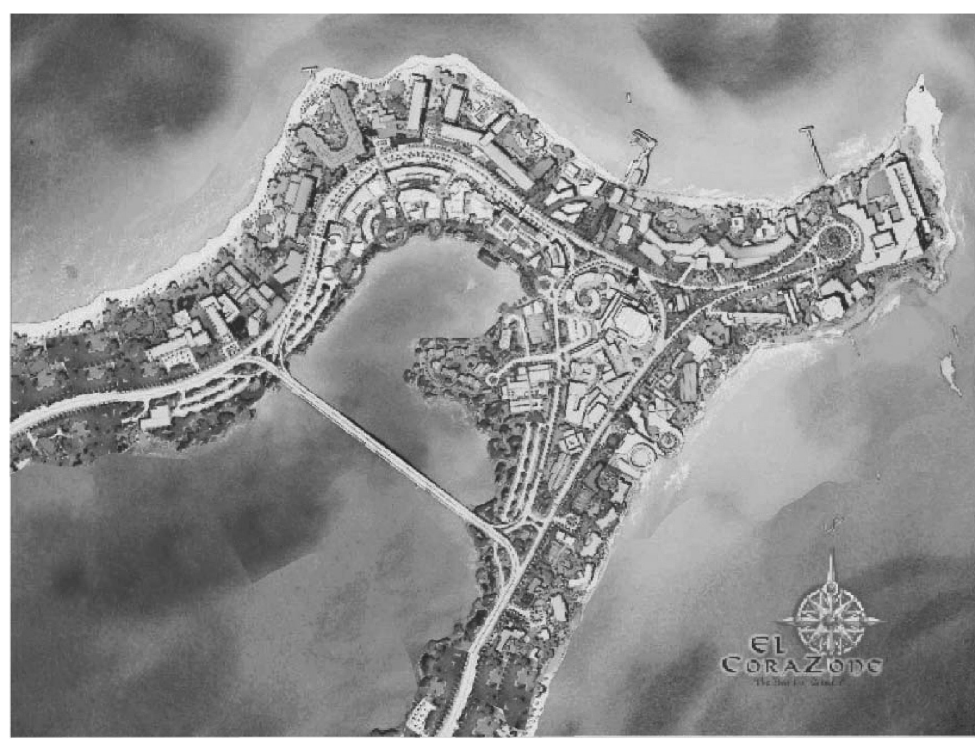

Fig.8: Proyecto conocido como "Corazone" y paso a desnivel sobre la Laguna Bojórquez y paseo comercial Fuente: Ayuntamiento Benito Juárez, 2001.

De todos los proyectos anteriormente descritos, actualmente solamente se percibe en construcción el hotel NH Krystal Cancún de 325 habitaciones en las parcelas 9 y 9A. La figura 4 presenta el proyecto de malecón o paseo peatonal frente a la laguna Bojórquez. Las figuras 5 y 6 presentan imágenes de los proyectos de ampliación de áreas verdes a lo largo del Blvd. Kukulkán, que corresponden al proyecto 2 .

La figura 8 presenta el proyecto del paso a desnivel sobre la laguna Bojórquez que implica rellenos y modificaciones mayores en el hábitat natural de la laguna Bojórquez.

El Programa Parcial de Reordenamiento Urbano Turístico de Punta Cancún 2001 no menciona los criterios que se tomaron para valorar el impacto ambiental que puede tener sobre el Sistema Lagunar Nichupté, la construcción del puente vehicular atravesándolo y la construcción de los rellenos para alojar lugares de estacionamiento sobre las lagunas. Asimismo no se mencionan medidas de mitigación o mejoramiento en el tema medioambiental.

No obstante, al seguir investigando los proyectos de Punta Cancún, se ha encontrado una presentación de un proyecto del cual se desconoce la autoría y que no forma parte de la legislación urbana de la ciudad de Cancún, sin embargo se podría decir que hace propuestas complementarias para el plan de desarrollo de Punta Cancún. Aquel proyecto se llama el Corazone y surge 
de la asociación de los propietarios de los hoteles y los comercios de Punta Cancún. Comprende una extensión de $2 \mathrm{~km}$. de longitud desde el Hotel Presidente Intercontinental hasta el Hotel Aristos, y cuenta con 17 hoteles que ofertan 4000 habitaciones y 14 centros comerciales con 657 comercios aproximadamente. Este grupo propone un ambicioso plan de desarrollo para rescatar ecológicamente la Laguna Bojórquez, solucionar el caos vial en Punta Cancún, mejorar la imagen urbana e incrementar los servicios públicos.

En el tema de rescate ecológico de la Laguna Bojórquez se propone la remediación del lecho lagunar mediante la separación de sedimentos en el lecho lagunar, la aireación y recirculación forzada por medio de la inyección de oxígeno desde el fondo lagunar, el bombeo de agua de mar y la fitoremediación a través de la poda de algas. También propone la rehabilitación y reparación del sistema de drenaje y las plantas de tratamiento de aguas residuales de la zona.

En cuanto al mejoramiento de la vialidad, propone ensanchar el Boulevard Kukulkán y construir un puente vehicular sobre la laguna. En cuanto al incremento de los servicios públicos se propone apoyar a Comisión Federal de Electricidad para la construcción de dos nuevas subestaciones, a la Organización de Agua Potable en la construcción de tres tanques elevados de agua potable y una red de drenaje público de mayor capacidad.

Es posible pensar que el proyecto de Corazone atiende algunas de las cuestiones que el Programa Parcial de Reordenamiento Urbano Turístico de Punta Cancún 2001 no dejaba claro. No es parte de la legislación vigente sin embargo hace propuestas que podrían traer una mayor aportación al mejoramiento de la Punta Cancún a mediano y largo plazo. No obstante no se sabe hasta qué punto se podrá desarrollar, si tendrá algún peso legal y en qué lapso de tiempo se esperan estas obras.

\section{CONCLUSIÓN}

Este artículo presentó la historia de la planificación turística en el litoral mexicano y el caso de estudio de Cancún, que se ha basado en muchos de los preceptos y políticas de la planificación urbana moderna y la planificación turística recomendada por la OMT. Los principios teóricos y buenas prácticas de la planificación turística de la OMT han sido recopilados por algunos estudiosos del fenómeno turístico y aplicados y adaptados con más o menos rigor al contexto mexicano.

Dentro de la generalización teórica de la disciplina de la planificación turística y urbana se ubicó el caso de la planificación turística mexicana llevada a cabo por el Gobierno Federal. En sus inicios, se encontró que la participación de FONATUR ha sido pieza clave en el desarrollo del litoral mexicano. No obstante, ha llevado a 
un proceso de desarrollo controlado por aquella agencia gubernamental, rígido en sus inicios por la incursión en la elaboración de un plan maestro bajo la tradición heredada del "zoning".

A través del caso de estudio de Cancún se ha desarrollado una metodología para la planificación de otros CCIIPP sobre el litoral mexicano. Sin embargo se puso de manifiesto que la metodología de la planificación turística de los años 70 ha cambiado e integrado aspectos que influyen y se relacionan con otros temas d el turismo de sol y playa y la planificación urbana actualmente.

Se presentó el Programa Parcial de Reordenamiento Urbano Turístico de Punta Cancún 2001, uno de los programas parciales que integran la legislación de la planificación de Cancún 2005. Aquel programa permitió la participación de un grupo de inversores en la elaboración de un proyecto para la Punta Cancún que se podría calificar como un acierto dentro del tema de incentivación a la participación ciudadana.

El Programa Parcial de Punta Cancún 2001 ejemplifica y resalta las prácticas en la planificación urbana de Cancún. Cabe hacer mención que quizá no haya sido un ejemplo representativo de todos estos planes y programas parciales que integra el Programa de Desarrollo Urbano del Centro de Población de la Ciudad de Cancún 2005, por el contrario, posiblemente se apuntó al caso más débil en el ejercicio con la finalidad de alertar, aprender lecciones y vislumbrar límites en la práctica.

A pesar de que la intención de que un grupo privado participe políticamente por el "bienestar" de su propiedad, se pueda calificar como positivo, se podría cuestionar si las propuestas de aquel documento son realmente acertadas, pertinentes y adecuadas para los objetivos planteados y para los objetivos que persigue la ciudad.

Es decir, si la solución a los problemas enlistados, sea la construcción de un nuevo hotel y la densificación de la construcción en Punta Cancún. O bien, si esta densificación vaya a repercutir a mediano y largo plazo positivamente no solamente en la economía de la ciudad. Así mismo, se podría poner en tela de juicio el impacto ambiental que podría traer el relleno y la construcción del puente vehicular sobre el sistema lagunar y comparar los costos y beneficios reales para la ciudad de Cancún.

Por lo anterior, se podría cuestionar hasta qué punto las autoridades municipales de Benito Juárez han podido integrar, ordenar y controlar la participación ciudadana en el proceso de planificación de la ciudad de Cancún. Surgen dudas y cuestiones acerca de la ponderación y el balance que debe o debería hacer la autoridad y la profundidad y seriedad con que se debería tratar cada caso en particular antes de promulgarse como ley. Surgen cuestionamientos acerca de la manera y razón de acotar la participación ciudadana hasta ciertas etapas del proceso de planificación. 
No obstante, al analizar el Proyecto del Corazone se han encontrado respuestas a algunas preguntas especialmente en el mejoramiento al medio ambiente y las redes de infraestructura. Éstas últimas son realmente las bases para alojar mayor número de habitaciones de hotel o mayores áreas comerciales. Este proyecto da sentido a algunas cuestiones acerca de los rellenos sobre la Laguna Bojórquez para estacionamientos. Al estudiar el Proyecto Corazone nos hemos percatado de que realmente la preocupación de este grupo podría ser la recuperación de los sedimentos contaminantes del fondo de la laguna y su confinamiento en dos áreas laterales.

De cualquier forma no se sabe hasta qué punto las intenciones del proyecto Corazone se vayan a llevar a la realidad ni con qué rigor se podría exigir que fueran llevadas a cabo por no encontrarse dentro de la legislación vigente. No todas las preguntas podríamos afirmar que tienen la respuesta correcta y pertinente, sin embargo el Proyecto Corazone da mayor sentido y complementaría positivamente las intenciones del Programa Parcial de Reordenamiento de Punta Cancún 2001.

Otra serie de preguntas surgen alrededor del tema de los riesgos que corren las autoridades locales al tratar de incorporar al ejercicio de la planificación urbana, los aspectos más recientes en la discusión teórica mundial como es la participación ciudadana y los nuevos grupos de actores en la escena del desarrollo turístico del litoral mexicano.

Posiblemente sea necesaria una evaluación más cautelosa y rigurosa por parte de las autoridades de la planificación urbana y regional a niveles nacional, estatal y municipal de la introducción de los temas que se encuentran sobre las mesas de discusión acerca del urbanismo y las tendencias de la planificación urbana en el mundo.

Cabe preguntar si es pertinente u oportuna la orientación que dan las autoridades estatales, y paraestatales en temas de planificación a las autoridades locales o municipales antes de que se promulguen planes generados por la influencia de las organizaciones privadas como parte de un plan de desarrollo urbano con peso legal. Tal vez no sea el momento de dejar que las autoridades municipales tomen toda la responsabilidad y la presión que los grupos privados pueden ejercer sobre ellas. O tal vez sea necesario pasar estas propuestas, planes y programas parciales por un análisis más crítico para llegar a las que realmente beneficien a la ciudad y formen parte de la ley.

Cabe hacer la pregunta acerca de la manera posible para que la participación ciudadana se pasara por un tamiz de la autoridad municipal y que esta tradujera en las distintas etapas, todas las intenciones y deseos de los distintos grupos interesados en cada zona a desarrollar de la ciudad (no solamente de un grupo en específico). 
Muchas preguntas quedan en el aire sin una respuesta única y correcta. Cullingworth et Nadin $(2002,12)$ afirman que no hay forma de determinar hasta qué punto el sistema de planificación urbana debería determinar cuánto, qué, dónde y cuándo. Sin duda, la última decisión es o debería ser política y debería estar sustentada en el marco social, económico y cultural de la región como cualquier otro estudio, gestión o acción que tenga repercusiones en el ámbito de la planificación urbana y regional. De igual forma son las autoridades las únicas que deberían evaluar y ponderar los beneficios y los costos reales para la población local, estatal y nacional y el medio ambiente construido y natural en aras del interés público.

\section{Bibliografía}

BARBA, R., PIÉ, R. (1996). "Arquitectura y Turismo. Planes y proyectos". CRPP, Barcelona.

BID. (1971). "Préstamo a Nacional Financiera S.A. Proyecto de infraestructura turística en Cancún". Banco Interamericano de Desarrollo. Documento del Secretario de Turismo al Comité de Prestamos, México.

CULLINGWORTH, B., NADIN. V. (2002). "Town and Country Planning in the UK". 13th Edition, Routledge, London.

FONATUR, Fondo Nacional de Fomento al Turismo. (2010). "Decreto de creación". URL: http://www. fonatur.gob.mx/es/quienes_somos/index.asp?modsec=01-DECRC\&sec=5[consultado mayo 2013]

FONATUR. (2006). "Planeación de Centros Turísticos. La experiencia y práctica de FONATUR". Fondo Nacional de Fomento al Turismo, Mexico, D.F.

FONATUR. (1982). "Cancún. Un desarrollo turístico en la zona turquesa". Cartografía y Servicios Editoriales, Fondo Nacional de Fomento al Turismo, México D.F.

GUNN, C. (1994). "Tourism Planning. Basics, concepts, cases". Third Edition, Taylor \& Francis, USA.

INSKEEP, E. (1991). "Tourism planning :an integrated and sustainable development approach". Van Nostrand Reinhold, New York.

LAWSON, F. (1995). "Hotels and Resorts. Planning, design and refurbishment". Butterworth Architecture, Oxford.

RAMÍREZ BLANCO, M. (1981). "Teoría General de Turismo". 3a Edición, Editorial Diana, México.

OMT. (2001). "Cooperación entre los sectores público y privado". Por una mayor competitividad del Turismo. Organización Mundial del Turismo, Consejo Empresarial OMT, Madrid.

PEARCE, D. (1989). "Tourism Development'. Second Edition. Longman Scientific \& Technical, New York.

UN. (1987). "Report of the World Commission on Environment and Development'. United Nations, General Assembly Resolution 42/187, 11 December 1987. Retrieved: 2007-04-12 URL: http://www. un.org/documents/ga/res/42/ares42-187.htm [Consultado mayo 2013] 
WILDAVKSY, A.B. (1987). "Speaking Truth to Power: The Art and Craft of Policy Analysis" (second edition), Transaction Publishers, Londres.

WTO. (1979). "Role and Structure of National Tourism Adminsitrations". World Tourism Organization, Madrid.

Guadalupe Aldape Pérez, Dra. Arquitecta Departamento de Urbanismo y Ordenación del Territorio (DUOT)

Universidad Politécnica de Cataluña (UPC)

Profesora de la Universidad de Las Américas, Puebla guadalupe.aldape@gmail.com 